\title{
Prevalent Nephrotic Syndrome
}

National Cancer Institute

\section{Source}

National Cancer Institute. Prevalent Nephrotic Syndrome. NCI Thesaurus. Code C122801.

Pre-existing nephrotic syndrome. 